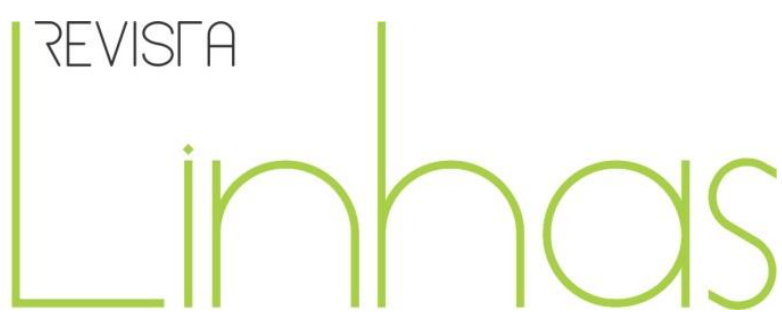

\title{
A pesquisa sobre o patrimônio histórico e educacional na Itália
}

\author{
Resumo \\ Esta contribuição tem como objetivo investigar e reconstruir as \\ razões que são a base do desenvolvimento, dentro das universidades \\ da península italiana, de uma linha específica de pesquisa científica e \\ didática universitária voltada para a coleta, preservação e valorização \\ do patrimônio histórico-educacional. Seguindo o modelo do que já \\ aconteceu em outras realidades acadêmicas europeias, o autor \\ também presta especial atenção ao nascimento na Itália da SIPSE, a \\ Sociedade Italiana para o Estudo do Patrimônio Histórico-Educacional.
}

\author{
Roberto Sani \\ Università degli Studi di Macerata \\ - Italia \\ roberto.sani@unimc.it
}

Palavras-chave: História da educação. Cultura material da escola.

Patrimônio cultural. Itália. Século XX.

\section{Para citar este artigo:}

SANI, Roberto. A pesquisa sobre o patrimônio histórico e educacional na Itália. Revista Linhas. Florianópolis, v. 20, n. 44, p. 75-95, set./dez. 2019. Título original: La ricerca sul patrimonio storico-educativo in Italia. Tradução do próprio autor. 


\title{
Research on historical and educational heritage in Italy
}

\begin{abstract}
This paper aims to investigate and reconstruct the reasons behind the development, within the universities of the Italian peninsula, of a specific line of scientific research and university teaching focused on the recovery, conservation and enhancement of historical heritage -educational. The author also pays particular attention to the birth in Italy, on the model of what has already happened in other European academic realities, of S.I.P.S.E., the Italian Society for the study of Historical-Educational Heritage.

Keywords: History of education. School material culture. Heritage. Italy. $\mathrm{XX}^{\text {th }}$ Centuries.
\end{abstract}




\section{1 - Os resultados mais amadurecidos de uma verdadeira revolução historiográfica: origens e desenvolvimentos da linha de pesquisa sobre patrimônio histórico e educacional na Itália}

A minha contribuição tem como objetivo principal destacar as razões que estão na base do lançamento, dentro das universidades italianas, de uma linha específica de pesquisa científica e didática universitária voltada para a coleta, preservação e valorização do patrimônio histórico-educacional.

$\mathrm{Na}$ Itália, como se sabe, os estudos e pesquisas sobre patrimônio históricoeducacional tiveram um desenvolvimento concreto apenas nos últimos tempos. A maioria deles, de fato, remonta aos últimos 10 a 15 anos, confirmando que estamos diante de uma corrente de investigação com uma história relativamente curta, cujas origens devem estar ligadas, de um lado, à verdadeira e própria revolução historiográfica que caracterizou nos últimos trinta anos os estudos sobre a história da educação e da escola e, por outro lado, mais particularmente, à influência peculiar exercida, mais recentemente, sobre a historiografia escolar e educativa italiana pela espanhola, na qual os estudos e pesquisas sobre o patrimônio há muito tempo são uma linha privilegiada e de indubitável importância, a ponto de favorecer a criação, em 2004, de uma sociedade científica específica, a SEPHE (Sociedad Española para o Estudo do Patrimônio HistóricoEducacional), ao lado da mais antiga e mais conhecida SEDHE (Sociedade Espanhola de História da Educação), que desde 1989 reúne historiadores da educação e da escola.

Quanto ao primeiro dos dois aspectos, deve ser lembrado que passamos, ao longo de um período de trinta anos:

- da história tradicional e até agora sem vida da escola, entendida essencialmente como a história das teorias e dos modelos institucionais de escola (uma história com um forte valor pedagógico, centrada acima de tudo no que "deveria ter sido", e não no que "realmente foi" nas diferentes fases históricas) à história mais articulada da legislação e das regulamentações, dos curricula, das práticas didáticas, das disciplinas e dos programas de ensino (SANI, 2008; SANI, 2013);

- para alcançar a história mais recente da cultura material da escola, que colocou no centro da investigação aspectos e ferramentas como: publicações especializadas e livros didáticos, imprensa dos periódicos para professores, cadernos escolares, 
bibliotecas de turma e de institutos, arquivos escolares, laboratórios e gabinetes científicos, mobiliário; até instrumentos científicos, mapas geográficos, cartazes murais e numerosos outros auxílios e apoios didáticos para o ensino (MEDAMONTINO-SANI, 2010; MEDA, 2012; MEDA-BADANELLI, 2013; MEDA, 2016);

- e, finalmente, para chegar a estudos ainda mais recentes focados na chamada memória escolar, no âmbito da qual os instrumentos, práticas e materiais receberam uma atenção inédita e se tornaram objeto de estudo (memórias, onomásticos públicos, arte lapidar e escritos expostos, decorações e honras ao mérito, obituários e as orações fúnebres, etc.) capazes de destacar qual memória da escola e do ensino tenha sido elaborada no contexto das representações oficiais e das comemorações públicas promovidas por instituições locais e nacionais com base em uma "política da memória" precisa, isto é, um "uso público do passado" que visava obter consenso e fortalecer o sentimento de pertencer a uma comunidade específica (VIÑAO FRAGO, 2005; ASCENZI-SANI, 2016; YANES CABRERA-MEDA-VIÑAO FRAGO, 2017).

Uma nova história, portanto, estabelecida nas últimas décadas e que tem sua referência privilegiada e essencial não mais nas teorias pedagógicas e nas filosofias da educação, mas na escavação arquivística e no uso de uma pluralidade de fontes materiais e imateriais - capazes de nos devolver a complexidade e variedade dos processos de formação escolar e das dinâmicas da alfabetização e aculturação nos diferentes níveis e ordens da escola.

Então, é fácil entender como, neste novo cenário historiográfico, mesmo o instrumento mais simples e o suporte didático mais banal e trivial adquirem, inevitavelmente, um significado hermenêutico específico e relevante, acabando por assumir a conotação de documento para reconstruir o passado e, ao mesmo tempo, de monumento, ou seja, de vestígio e testemunho, de cuja recuperação, preservação e valorização depende a própria possibilidade de reconstruir esse passado (através da pesquisa histórica) e, contemporaneamente, de recuperar e disponibilizar a todos e a cada um a memória individual e coletiva de uma instituição ou evento capaz de aumentar a conscientização e a consciência crítica do indivíduo e da comunidade (LE GOFF, 1978). 


\section{2 - A centralidade da abordagem historiográfica nos estudos sobre o patrimônio histórico-educacional contra todas as formas de simplificação e reducionismo}

Neste ponto, porém, devemos nos perguntar: do que estamos falando, quando falamos de herança histórico-educacional? Recentemente, tanto na Espanha quanto em Portugal, refiro-me às pesquisas e aos estudos de Agustín Escolano (ESCOLANO, 2007; ESCOLANO, 2010; ESCOLANO, 2010), Antonio Viñao Frago (VIÑAO FRAGO, 2010; VIÑAO FRAGO, 2012), Julio Ruiz Berrio (RUIZ BERRIO, 2000; RUIZ BERRIO, 2010) e Maria João Mogarro (MOGARRO, 2013; MOGARRO, 2014), como também na Itália com as investigações e reflexões de Juri Meda (MEDA, 2010; MEDA, 2013; MEDA, 2014) e de Marta Brunelli (BRUNELLI, 2013; BRUNELLI, 2016; BRUNELLI, 2016; BRUNELLI, 2018), os estudiosos que mais trabalharam com essa área de pesquisa formularam uma série de propostas interessantes sobre uma definição compartilhada e mais ampla e inclusiva possível da noção de patrimônio histórico-educacional, de forma - para retomar a síntese mais recente e ágil de Juri Meda - a incluir não apenas "a ampla gama de ferramentas e objetos pertencentes ao contexto do aluno", como também a "todos os outros instrumentos de escrita" que "não são conservados nas escolas, mas nas casas"; e mais uma vez os "móveis escolares (cadeiras, quadros negros, carteiras), [os] subsídios didáticos, [os] instrumentos científicos e [as] mobílias de vários tipos", bem como as "bibliotecas escolares", os "arquivos escolares" e os "edifícios históricos que podem servir de sede das escolas" (MEDA, 2017).

Em suma, uma classificação largamente abrangente e de amplo espectro, para ser, sem dúvida, mantida nas pesquisas relativas ao patrimônio; em relação ao qual só se poderia objetar que, como tendo sido necessariamente emprestada das pesquisas e estudos sobre a história da instituição escolar, certamente se mostra exaustiva em relação ao patrimônio strictu sensu escolástico, muito menos no lugar em que nos referimos ao "patrimônio educacional" mais abrangente, no âmbito do qual também inclui espaços, formas e instrumentos da educação não-escolar, tais como a educação ministrada em estruturas assistenciais e reeducativas, como orfanatos, conservatórios femininos e instituições para menores delinquentes ou em instituições educacionais 
especiais, como no caso dos oratórios paroquiais e das organizações juvenis de orientação laica e socialista (SANI, 2016).

Definido, embora em suas linhas gerais, o objeto de nossa investigação, é necessário identificar o papel do historiador - e da investigação de caráter historiográfico - no processo de coleta, preservação e valorização do patrimônio histórico-escolar e educacional; uma necessidade, esta última, decorrente do fato de que um processo semelhante envolve de diversas maneiras não só o profissionalismo e as diferentes habilidades, em primeiro lugar aquelas que se referem ao campo pedagógico e metodológico e que operam ao lado da educação para o patrimônio e da didática do patrimônio cultural escolástico (BRUNELLI, 2014); mas também do fato de que uma linha de estudo como a do patrimônio histórico-educacional está claramente exposta aos riscos de indeterminação interpretativa, ou melhor, da perda de uma ancoragem efetiva no campo historiográfico.

Conforme veio à tona a partir de alguns estudos que surgiram recentemente no cenário internacional, de fato, a tentação é substituir uma abordagem estritamente historiográfica (certamente muito desafiadora!) com uma abordagem antropológica, etnológica, semiótica etc., que inevitavelmente tende a perder a consciência de que apenas uma leitura em uma chave autenticamente histórica do patrimônio escolar e educacional pode nos restituir o significado mais autêntico de tal patrimônio. Daí a escolha de colocar no centro da nossa reflexão uma espécie de pré-condição metodológica ou, melhor dizendo, uma referência precisa à verdadeira e própria centralidade da abordagem historiográfica.

Identificar e especificar o papel e as funções do histórico da escola e da educação nas diversas fases da coleta, preservação e valorização do patrimônio histórico-escolástico e educacional, a esse respeito, significa não só evitar confusões e sobreposições de competências, mas também evidenciar a necessidade, em todas as fases do processo, do que poderíamos definir como supervisão historiográfica.

Não é necessário recordar, por exemplo, que é tarefa do historiador da escola e da educação identificar os materiais coletados (instrumentos, documentos, maquinários, mobiliário, etc.) e fornecer sobre cada um deles as informações que serão destinadas a preencher a ficha de identificação (idade, função, possível colocação no contexto escolar 
em determinada época, etc.); assim como cabe ao mesmo especialista destacar o contexto cultural e propriamente "escolástico" dentro do qual o objeto ou conjunto de instrumentos ou documentos recuperados encontram seu lugar e seu significado mais autêntico.

Não menos decisivo é o papel que o mesmo historiador da escola e da educação é chamado a exercer quando pretende criar um projeto orgânico de preservação dos materiais coletados através da preparação de coleções permanentes específicas dos mesmos nos locais de origem, como no caso de coleta e restauro, para fins expositivos e didáticos, dos antigos gabinetes de física ou química, ou dos museus de história natural preservados nos Ginásios-Liceus e nos institutos técnicos tradicionais que surgiram durante o século XIX ou início do século XX; ou, sempre com o objetivo de preservar uma coleção rica e variada de ferramentas didáticas e mobiliário escolar, propõe-se a criação de instalações adequadas e apropriadamente identificadas, um verdadeiro museu da escola e da didática.

Nesse caso, junto com elaboração de fichas de identificação dos vários materiais e descobertas gradualmente coletados ou adquiridos ex novo, a tarefa do historiador será garantir que, tanto a exibição, em mostruários ou arquivadores, de achados individuais ou coleções completas de materiais e mobiliário, bem como a preparação de espaços especiais destinados a "recriar" lugares e cenários da escola do passado (como no caso de um gabinete de física ou de um museu de história natural do final do século XIX; ou de uma sala de aula do período fascista etc.) sejam rigorosas e totalmente confiáveis em termos de reconstrução histórica, bem como constantemente adaptadas aos locais mais recentes e influentes da historiografia escolástica e educacional internacional ( $M$. SOMOZA RODRÍGUEZ, 2013; ASCENZI-BRUNELLI-MEDA, 2018).

Somente nessa condição, de fato, as coletas individuais e as coleções de achados e os museus escolares e didáticos propriamente ditos poderão garantir ao usuário, além do apreciável impacto visual e emocional, a real recuperação do passado e seu uso com a finalidade de promover a memória e a identidade.

Uma garantia similar de exatidão filológica e rigor historiográfico deverá ser assegurada pelo historiador da escola e pela educação na preparação dos catálogos de museus apropriados e qualquer outro material de apresentação das mostras e exposições 
feitas no contexto desses projetos de recuperação e preservação do patrimônio (LICEO GINNASIO, 2006; LICEO GINNASIO, 2008).

Finalmente, o papel que o historiador da escola e da educação é chamado a desempenhar no contexto das iniciativas e processos de desenvolvimento do patrimônio parece mais complexo. Levando em conta, de fato, que nesse cenário estejam inseridos tanto o projeto quanto a implementação e gestão concreta dos diversos percursos educacionais que utilizam o patrimônio histórico-educacional para transmitir conhecimentos e habilidades (PIZZIGONI, 2012), bem como o aprofundamento do horizonte teleológico e axiológico da formação promovida através do uso consciente do próprio patrimônio, é fácil entender como, neste caso, as habilidades pedagógicas e metodológicas que operam nos contextos da didática do patrimônio cultural das escolas e da educação para o patrimônio exerçam um domínio maior (BRUNELLI, 2018, p. 44-89).

No entanto, deve-se notar que no âmbito da valorização do patrimônio estão incluídos também os percursos universitários destinados à formação inicial de futuros professores de escolas de todos os níveis e graus e da formação em busca de futuros pesquisadores e especialistas em história da escola e da educação, é fácil entender como as competências específicas do historiador provam ser mais uma vez indispensáveis para a determinação de itinerários específicos de formação (ciclos de palestras e seminários, estágios, exercícios sobre as fontes etc.) visando a aquisição de habilidades profissionais indispensáveis.

Além disso, não é coincidência que, seguindo o modelo do que já foi experimentado há algum tempo na Espanha e em outros países europeus e não europeus, em algumas universidades da península, tanto os cursos de estudo em Ciências da Educação Primária quanto os cursos post lauream destinados à formação profissional de professores do ensino médio (referimo-nos aos chamados Percursos Formativos Integrados de $24 \mathrm{CFU}$ ), como os doutorados de pesquisa na área das Ciências da Educação introduziram com excelentes resultados ciclos de palestras, seminários e treinamentos práticos voltados ao patrimônio histórico-educacional (ASCENZI-PATRIZI, 2014).

É claro, no entanto, que ainda há muito a ser feito. Não há dúvida de que algumas escolhas feitas recentemente na Itália, como no caso da fundação da SIPSE, a Sociedade 
Italiana para o Estudo do Patrimônio Histórico-Educacional, trazem um bom presságio para o futuro próximo.

\section{3 - Três desafios prioritários para os estudos sobre patrimônio histórico- educacional: a organização e o fortalecimento da pesquisa, o impulso à internacionalização, a formação de pesquisadores}

Fundada por ocasião da III Conferência Internacional sobre Cultura Material Escolar, realizada em Macerata em 12 e 13 de setembro de 2017 (POMANTE-BRUNELLI, 2017), por iniciativa das unidades de pesquisa da história da educação e da escola que operam junto a uma dúzia de universidades italianas (Bari, Basilicata, Bolonha, Bolzano, Calábria, Florença, Foggia, Macerata, Católica de Milão, Molise, Pádua e Roma Tre), a SIPSE, com base no modelo SEPHE e de associações científicas semelhantes que surgiram nos últimos anos em Portugal, França, Reino Unido, Grécia, Argentina, Chile e Brasil, tem como principal objetivo promover estudos e pesquisas sobre o patrimônio históricoeducacional da península e de formar uma nova geração de pesquisadores e especialistas no setor (BRUNELLI, 2017).

Nesse sentido, várias motivações foram importantes para a escolha da fundação da SIPSE. Em primeiro lugar, a consciência do grave atraso acumulado na Itália no âmbito dos estudos sobre o patrimônio e, em particular, da dramática falta de infraestruturas e ferramentas para a implementação da pesquisa neste setor e para a formação especializada de pesquisadores.

A percepção de um enorme vazio a ser preenchido acompanhou, no entanto, a conscientização de que, em face das necessidades urgentes acima mencionadas, não era possível prosseguir em ordem aleatória nem depender exclusivamente do trabalho (embora apreciável e, em alguns casos, de grande valor!) de algum estudioso muito merecedor ou de alguma unidade de pesquisa local isolada: somente a sinergia total e a colaboração plena e constante entre os grupos de historiadores da escola e da educação das principais universidades da península teria possibilitado a implantação de um projeto ambicioso de implementação e fortalecimento das pesquisas e dos estudos nessa área. 
Daí a verdadeira centralidade da SIPSE, que, no entanto, se realmente quer guiar o crescimento do setor de estudos e da comunidade de estudiosos e pesquisadores que se referem a esse setor, especialmente neste delicado momento histórico, deve concentrar a sua atenção e fortalecer seu compromisso com todas as questões relacionadas à pesquisa, deixando em segundo plano questões muito menos urgentes e decisivas do que a representação de seus próprios membros na frente acadêmica e institucional, áreas nas quais outros órgãos representativos já operam, como no caso do Centro Italiano de Pesquisa Histórico-Educacional (CIRSE) e da Sociedade Italiana de Pedagogia (SIPED), para ser caracterizada exclusivamente como ponto de referência e espaço de comparação e crescimento para a comunidade científica do setor, a partir de uma série de objetivos:

- a fomentação da comparação científica e cultural dos vários centros acadêmicos, das diferentes tradições de estudo e dos diferentes grupos de pesquisa presentes nessa área (a atribuição do patrocínio SIPSE a iniciativas culturais e científicas de qualidade, etc.);

- o fortalecimento e a coordenação de amplas atividades de pesquisas e processos de internacionalização (grandes projetos de pesquisa envolvendo colaboração plurianual, inclusive internacional, etc.);

- por último, mas não menos importante, a ativação e acreditação de cursos especiais de formação para jovens pesquisadores (doutorado de pesquisa; experiências de pós-doutorado, colaborações internacionais, etc.).

Naturalmente, não é possível, aqui, examinar esses objetivos em detalhes. O que nós modestamente acreditamos que é possível fazer é tentar identificar, para cada um deles, as iniciativas e estratégias prioritárias que nos permitirão iniciar o processo de impulsionamento do crescimento e fortalecimento do campo de estudos.

No que diz respeito ao fomento da comparação científica e cultural dentro da comunidade acadêmica e à valorização das diferentes tradições de estudo e dos diferentes grupos de pesquisa que atuam no âmbito do patrimônio histórico-educacional, a SIPSE é chamada a realizar uma tarefa prioritária: estimular o confronto interno e suscitar o debate e a discussão entre as unidades de pesquisa da história da educação e 
da escola que operam nas diversas universidades em torno dos novos rumos para a historiografia do setor e em torno das grandes linhas de pesquisa que caracterizam a cenário internacional.

Uma comparação completa para um refinamento indispensável das metodologias e para um delineamento mais preciso dos objetivos da pesquisa, que envolva toda a comunidade científica dos historiadores da educação e da escola da península: este é o objetivo básico a ser atingindo, o que parece ser tão oportuno e urgente, quanto mais é possível verificar, na comunidade numericamente reduzida e fragmentada de pesquisadores e docentes de história da educação e da escola que operam nas universidades italianas, sinais evidentes de isolamento e retrocesso no contexto local, com a consequente renúncia para exercer um papel na pesquisa científica em nível nacional e internacional.

A fim de fortalecer e aperfeiçoar os estudos sobre o patrimônio histórico-escolar e educacional, a SIPSE também é chamada a exercer uma função adicional e indispensável: fomentar e incrementar um confronto sólido e uma estreita colaboração entre os estudiosos e pesquisadores universitários e aqueles sujeitos e instituições que, de formas diferentes, mas muitas vezes com grande rigor e consciência, colocaram no centro de seus compromissos como professores, bibliotecários, arquivistas, administradores escolares e funcionários da administração pública a coleta, preservação e valorização do patrimônio histórico-escolar e educacional.

A este respeito, o recente seminário sobre o tema Experiências e reflexões sobre o patrimônio histórico-educacional das escolas como fonte para o ensino da história, organizado em Nápoles no dia 6 de abril de 2018 pela Associação das Escolas Históricas Napolitanas em colaboração com a SIPSE, mostrou o extraordinário potencial de uma estreita conexão entre o mundo das escolas e das instituições culturais que operam no território com o mundo da pesquisa universitária para o aprofundamento dos temas mencionados acima (PACIARONI, 2018).

Também no âmbito da investigação científica de alto perfil e dos processos de internacionalização, a SIPSE é chamada a exercer uma função de importância primordial, exortando os estudiosos da história da educação e da escola que operam nas várias universidades da península a se engajarem na área dos PRIN, ou seja, os Projetos de 
Pesquisa de Interesse Nacional, e nos programas de pesquisa ainda mais ricos e promissores financiados pela União Europeia, bem como para não esquecer os programas de financiamento mais modestos patrocinados pelo Ministério da Educação, da Universidade e da Pesquisa (MIUR) ou das regiões no quadro de iniciativas e projetos para a preservação e valorização das instituições escolares do território e do patrimônio cultural local.

Com o propósito de lançar percursos de internacionalização autênticos e significativos, capazes de proporcionar um salto qualitativo real nos estudos sobre o patrimônio e evitar a repetição das experiências grotescas e embaraçosas de pseudointernacionalização que, ao longo dos últimos quinze anos, marcaram nosso setor científico-disciplinar, sem proteger nem mesmo o campo histórico-pedagógico de inserção interna.

Desse modo, o fortalecimento de conexões com outras sociedades científicas do setor, europeias e não europeias, e o confronto direto e constante com estudiosos e grupos de pesquisa que, nos vários países trabalham com os mesmos temas, constituem apenas o primeiro passo de uma estratégia destinada a conduzir inevitavelmente - se não quisermos reduzir tudo à mera adesão a qualquer call for papers estrangeira ou para a publicação, una tantum, de uma monografia ou de uma coleção de ensaios com autores ou curadores de diferentes nacionalidades - a criação de verdadeiras equipes de pesquisa supranacionais e a promoção de projetos de pesquisa realmente ambiciosos, capazes de lidar com temas e questões abrangentes sem - ou somente - passar essencialmente por uma perspectiva inevitavelmente nacional (ou mesmo local), mas à luz de uma abertura original e inédita para o cenário europeu; uma abertura que parece ser muito apropriada às questões relativas ao patrimônio histórico-escolar e educacional, evidenciada pelas raras contribuições de natureza histórico-comparada surgidas nos últimos anos nesta área.

Nesse sentido, finalmente, a ativação e o credenciamento de cursos especiais de formação para jovens pesquisadores do setor, no atual clima político e cultural que tem, de um lado, a universidade italiana como um todo marcada por uma profunda crise de identidade e, por outro lado, a introdução por parte do MIUR e através da Agência Nacional de Avaliação do Sistema Universitário e de Pesquisa (ANVUR) de sistemas de 
avaliação das universidades e de verificação da qualidade da pesquisa científica universitária fortemente burocratizada e caracterizada por uma atenção obsessiva para satisfazer medianas, alcançar limiares, ficar em certas parâmetros formais, satisfazer indicadores bibliométricos específicos ou de outra natureza, uma modificação radical dos modos e formas tradicionais de treinamento para a pesquisa de jovens acadêmicos parece ser cada vez mais apropriada (SANI, 2017).

Em outras palavras, uma escolha criativa é necessária para contrastar as estratégias e práticas adotadas até agora. Essa escolha deve tentar ir além das obrigações formais e meramente burocráticas estabelecidas pelo MIUR e pela ANVUR, e restituir à nossa comunidade científica - e particularmente aos estudiosos do patrimônio históricoescolar e educacional -, em virtude de uma escolha não burocrática, mas de autêntica competência científica, a tarefa de delinear itinerários e programas de formação e treinamento para a pesquisa das novas gerações de estudiosos, com base em critérios e diretrizes compartilhados e reconhecidos nacional e internacionalmente.

Lembramos que a estratégia que temos em mente não pretende desobedecer às normas e aos regulamentos em vigor nem contrastar o sistema atual que, em nosso país, regulamenta o recrutamento e a formação de jovens pesquisadores, pois, de forma mais convincente, aproveita lacunas e deficiências do sistema atual, que muitas vezes é incapaz de oferecer um programa pontual de objetivos ambiciosos e substanciais para o cumprimento das obrigações formais.

Quanto ao doutorado de pesquisa, em primeiro lugar, com o consentimento e a estreita colaboração das unidades de pesquisa sobre o patrimônio histórico-escolar e educacional operado nas várias universidades italianas e sem modificar a atual estrutura burocrática e administrativa que o doutorado apresenta nas várias universidades da península, a SIPSE poderia assumir a função de entidade certificadora para a qualidade do percurso de formação e treinamento fornecido e dos conhecimentos e habilidades adquiridos sobre o assunto, como o que já ocorre na qualificação para a profissão ou a atualização nas categorias de profissionais (jornalistas, médicos, advogados etc.) que possuem uma ordem profissional reconhecida.

Tendo em vista o fato de que, no atual sistema, não existem mais cursos individuais, muito menos escolas de doutorado altamente especializadas, já que, um 
pouco em todas as universidades a tendência é agregar em macrorrecipientes diferentes tipos de cursos (Ciências Humanas, Educação e assim por diante), compreendemos como a tarefa da SIPSE seja acima de tudo estabelecer um registro nacional de bolsas de estudo individuais no campo da história da educação e da escola dedicado a teses de doutorado sobre o patrimônio histórico-educacional.

Cabe, então, à mesma sociedade científica delinear um percurso formativo de três anos, adicional e integrado em relação ao percurso estabelecido pelo único provedor da bolsa de doutorado, que será o mais capacitado e efetivo no nível científico e cultural, quanto mais possa envolver no percurso de formação e treinamento para a pesquisa com base numa oferta selecionada de ciclos de aula, participação em conferências e seminários, oficinas e estágios em arquivos e bibliotecas especializados, museus escolares e didáticos, etc. - as unidades de pesquisa do patrimônio que operam nas várias universidades da península e algumas das unidades de pesquisa, entre aquelas com qualificações superiores, presentes na Europa.

Na conclusão de um tal curso de doutorado de pesquisa, que também deve incluir, para completar o ambicioso projeto, a possível publicação da tese de doutorado - sujeita à sua avaliação por uma comissão internacional designada pela própria SIPSE - em uma compilação de monografias ou em uma revista científica internacional de grande prestígio, a mesma sociedade científica do setor deve certificar oficialmente a qualidade científica do percurso de doutorado realizado e os altos objetivos alcançados, cuja certificação, longe de constituir um mero reconhecimento de natureza formal, teria o mérito mais relevante de representar o resultado de uma avaliação de competência formulada, através de sua sociedade científica de referência, pela comunidade de estudiosos do setor.

Nos moldes do curso de doutorado, e por delegação das mesmas unidades de pesquisa sobre o patrimônio histórico-escolar e educacional em funcionamento nas várias universidades da península, a SIPSE poderia criar cursos especiais de formação e treinamento para a pesquisa de pós-doutorado, também em acordo com a SEPHE e com as outras sociedades científicas do setor que operam em Portugal, França, Reino Unido etc., percursos de internacionalização e colaboração para a pesquisa supranacional. 


\section{4 - Conhecer para preservar e valorizar o patrimônio histórico-educacional da península: o projeto de um recenseamento do patrimônio cultural da escola e das instituições assistenciais e educativas para a infância e a juventude na Itália}

Há um último aspecto sobre o qual parece apropriado chamar a atenção. Sem dúvida, entre as necessidades principais e mais urgentes que caracterizam o setor dos estudos sobre o patrimônio histórico-educacional, destaca-se a necessidade de realizar o censo do patrimônio da escola e da educação presentes no território nacional. Essa operação não é algo fácil de realizar, dado o estado de abandono ou, como também, a ausência de inventário e catalogação que caracteriza a maior parte dos materiais e mobiliário que seriam objeto do censo e, ao mesmo tempo, a grave falta de recursos humanos e financeiros para investir em tal empreendimento.

É verdade, no entanto, que um conhecimento profundo das dimensões e características do patrimônio histórico-educacional nacional é, para todos os efeitos, uma operação tão oportuna quanto necessariamente preliminar em vista da criação de uma pesquisa sistemática e de estudos orgânicos sobre o patrimônio em si.

A proposta, que aqui nos permitimos fazer, é criar um vasto e ambicioso Recenseamento dos bens culturais da escola e das instituições assistenciais e educacionais para a infância e a juventude ou, de forma mais abrangente, do patrimônio históricoeducacional do nosso país, que tenha como artífices e protagonistas - talvez sob a égide da SIPSE - as unidades de pesquisa de história da educação e da escola que operem nas várias universidades da península e que, sob sua direção e coordenação, envolvam de várias maneiras, no levantamento e inventariação dos bens patrimoniais presentes em cada centro urbano ou no território provincial e regional mais amplo, estudantes universitários, formandos e doutorandos de pesquisa, mas também professores de todos os tipos e níveis de escola, arquivistas e bibliotecários.

Um empreendimento semelhante, destinado a ser realizado ao longo de, pelo menos, uma década e concentrado principalmente no trabalho de levantamento e inventariação completa dos bens patrimoniais realizados localmente através do envolvimento de um grande número de colaboradores, precisa, em nossa opinião, de 
uma série de ações e procedimentos preliminares e, por diversas razões, indispensáveis para o seu pleno êxito:

- a constituição de um comitê científico internacional (que poderia ser composto por alguns dos principais especialistas italianos e estrangeiros em estudos sobre o patrimônio), que assumisse a direção e a coordenação científica de todo o projeto;

- a constituição de um comissão técnico-científica nacional (que poderia ser formada pelos representantes das unidades de pesquisa das universidades envolvidas no empreendimento), que assumisse a delicada tarefa de elaborar e validar os registros de reconhecimento dos bens patrimoniais a serem identificados no censo;

- a preparação, através de uma editora de alto perfil, de uma série de publicações especializadas que acolha e aprimore adequadamente os resultados do censo, ou que publique em volumes individuais escritos com rigor científico e acompanhados por ensaios introdutórios apropriados, tabelas e ilustrações, inventários e catálogos relativos aos bens patrimoniais atualmente conservados em institutos escolares antigos (por exemplo: museus naturais, gabinetes de física ou química, mobiliário e instrumentos didáticos de salas de aula, bibliotecas específicas ou dos institutos, arquivos escolares, etc.), coletas e coleções de instrumentos, móveis, documentos e objetos de vários gêneros exibidos em museus da escola, da didática e da educação; eventuais fundos patrimoniais privilegiados de propriedade de colecionadores particulares (por exemplo: coleções de cadernos escolares ou livros didáticos ou outros materiais e instrumentos do material escolar pertencente aos colecionadores); finalmente, o mobiliário escolar e os instrumentos escolares e didáticos conservados por vários motivos em armazéns, depósitos e outros centros de coleta. 


\section{Conclusões}

No início dos anos oitenta, como se sabe, na introdução ao seu trabalho fundamental sobre Escola, cultura e política, de De Sanctis a Gentile, um estudioso refinado que estava particularmente atento à história da historiografia escolástica italiana e europeia, como era Marino Raicich, traçou um quadro altamente crítico - e às vezes implacável - do estado dos estudos histórico-educacionais na Itália, enfatizando, entre outras coisas, como o nosso país carecia de uma organização séria da pesquisa nessa área e de como ainda fizessem falta as ferramentas indispensáveis (repertórios, coletas de fontes, etc.) para uma investigação histórica capaz de ir além das sínteses apressadas e superficiais e de fornecer contribuições abrangentes:

O estudioso escreveu que a produção de historiadores e educadores sobre os temas da história das instituições educacionais é ampla; no entanto, parece-me que tenho que concordar plenamente com o que foi observado [...] em torno da pobreza dos estudos na Itália sobre a história da instituição escolar. Temos muito pouco de válido; nem acho que devemos levar em conta as histórias breves e ocasionais, compêndios ad usum delphini, escritos apressadamente sobre a "onda" do ano de 1968 (RAICICH, 1982, p. 19-26).

Quase quarenta anos depois da denúncia feita por Marino Raicich, parece não haver dúvidas de que as graves deficiências organizacionais e metodológicas denunciadas e a "pobreza dos estudos" que encontrou na história da escola e da educação tenham sido agora - e por um longo tempo - completamente superadas e, portanto, constituem apenas uma memória inconveniente.

É verdade, no entanto, que a mesma falta de uma organização de pesquisa séria (fontes, ferramentas, infraestruturas, etc.) pode ser encontrada hoje, na Itália, no contexto dos estudos sobre o patrimônio histórico-educacional.

Daí o desafio para a SIPSE, para as unidades de pesquisa do setor presentes nas várias universidades da península e para cada um de nós de trabalhar duro e agir, em diferentes níveis, para que as carências e lacunas organizacionais e metodológicas sejam preenchidas e, também na península, os estudos sobre o patrimônio históricoeducacional possam dar um salto qualitativo imprescindível. 


\section{Referências}

ASCENZI, Anna; BRUNELLI, Marta; MEDA, Juri. Représentation du passé scolaire dans les musées de l'école en Italie, In: Première Rencontre francophone des musées de l'école. Actes, Futuroscope. Chasseneuil-du-Poitou: Canopé Editions, 2018, p. 45-54.

ASCENZI, Anna; PATRIZI, Elisabetta. I musei della scuola e dell'educazione e il patrimonio storico-educativo. Una discussione a partire dall'esperienza del Museo della Scuola «Paolo e Ornella Ricca» dell'Università degli Studi di Macerata, History of Education \& Children's Literature. Macerata: Eum, v. 9, n. 2, p. 685-714, 2014.

ASCENZI, Anna; SANI, Roberto. Between rhetoric celebration and social marginalization. The teachers' and headmasters' memory and celebration through the obituaries published in the school and teachers' magazines in the first century after the unification (1861-1961). History of Education \& Children's Literature. Macerata: Eum, v. 9, n. 2, p. 97117, 2016; v. 11, n. 2 p. 121-150, 2016.

BRUNELLI, Marta. La catalogazione dei «beni culturali» della scuola: questioni metodologiche e concettuali. In: CAVALLERA, Hervé Antonio (a cura di). La ricerca storico-educativa oggi. Un confronto da metodi, modelli e programmi di ricerca. LecceBrescia: Pensa MultiMedia, 2013, v. I, p. 193-218.

BRUNELLI, Marta. Heritage Interpretation. Un nuovo approccio per l'educazione al patrimonio. Macerata: Eum, 2014.

BRUNELLI, Marta. La comunicación y la interpretación del patrimonio educativo en los museos: espejo y reflejo de una disciplina en la transformación. In: DAVILA, Paulí; NAYA, Luis María (ed.). Espacios y patrimonio histórico-educativo. San Sebastián: Erein, 2016, p. 79-95.

BRUNELLI, Marta. La recente costituzione della Società Italiana per lo studio del Patrimonio Storico-Educativo (SIPSE). History of Education \& Children's Literature. Macerata: Eum, v. XII, n. 2, p. 653-665, 2017.

BRUNELLI, Marta. Pour une histoire de la production industrielle des matériels didactiques en Italie de la fin du XIXe à la première moitié du XXe siècle: premières indications et perspectives de recherche. In: FIGEAC-MONTHUS, Marguerite (ed.). Education et culture matérielle en France et en Europe di XVle siècle à nos jours, Paris: Honoré Champion, 2018, p. 109-132.

BRUNELLI, Marta. L'educazione al patrimonio storico-scolastico. Approcci teorici, modelli e strumenti per la progettazione didattica e formativa in un museo della scuola. Milano: Franco Angeli, 2018.

ESCOLANO BENITO, Agustín (ed.). La cultura material de la escuela. En el centenario de la JAE, 1907-2007. Berlanga de Duero: C.E.I.N.C.E., 2007. 
ESCOLANO BENITO, Agustín. La cultura material de la escuela y la educación patrimonial. Educatio Siglo XXI. Revista de la Facultad de Educación de la Universidad de Murcia. Murcia: University press, v. 28, n. 2, p. 43-64, 2010.

ESCOLANO BENITO, Agustín. Sherlock Holmes goes to school. Etnohistory of school and educational heritage, History of Education \& Children's Literature. Macerata: Eum, v. 5, n. 2, p. 17-32, 2010.

LE GOFF, Jacques. Documento/Monumento. In. Enciclopedia. Torino: Einaudi, 1978, v. V, p. 38-43.

LICEO GINNASIO «VITTORIO EMANUELE II» DI NAPOLI - ISTITUTO ITALIANO PER GLI STUDI FILOSOFICI. II Museo di Storia Naturale «G. Mercalli». Napoli: Nella Sede dell'Istituto, 2006.

LICEO GINNASIO «VITTORIO EMANUELE II» DI NAPOLI - ISTITUTO ITALIANO PER GLI STUDI FILOSOFICI. II Museo del Gabinetto di Fisica e Chimica «L. Ciccone». Napoli: Nella Sede dell'Istituto, 2008.

MEDA, Juri. Il patrimonio storico-educativo: oggetti da museo o fonti materiali per una nuova storia dell'educazione?, relazione presentata al Seminario di studi sul tema: «Itinerari nella storiografia educativa» (Bari, 10-11 aprile 2017), in press.

MEDA, Juri. La «historia material de la escuela» como factor de desarollo en la investigación histórico-educativa en Italia. In.: MORENO MARTÍNEZ, Pedro Luis; SEBASTIÁN VICENTE, Ana (ed.). Patrimonio y Etnografía de la escuela en Españ y Portugal durante el siglo XX. Murcia: SEPHE-CEME de la Universidad de Murcia, 2012, p. $17-32$.

MEDA, Juri. La conservazione del patrimonio storico-educativo: il caso italiano. In: MEDA, Juri; BADANELLI, Ana Maria (ed.). La historia de la cultura escolar en Italia y en España: presupuestos y perspectivas. Actas del I Workshop Italo-Español de Historia de la Cultura Escolar (Berlanga de Duero, 14-16 de noviembre de 2011). Macerata: Eum, 2013, p. 167-198.

MEDA, Juri. Musei della scuola e dell'educazione. Ipotesi progettuale per una sistematizzazione delle iniziative di raccolta, conservazione e valorizzazione dei beni culturali delle scuole, History of Education \& Children's Literature. Macerata: Eum, v. V, n. 2, 489-501, 2010.

MEDA, Juri. "School museums, museums of education and historical educational heritage. A discussion from the experience of the «Paolo and Ornella Ricca» School Museum of the University of Macerata", History of Education \& Children's Literature, IX/2 (2014), 685-714.

MEDA, Juri. Mezzi di educazione di massa. Saggi di storia della cultura materiale della scuola tra XIX e XX secolo. Milano: Franco Angeli, 2016. 
MEDA, Juri; MONTINO, Davide; SANI, Roberto (ed.). School Exercise Books. A Complex Source for a History of the Approach to Schooling and Education in the 19th and 2oth Centuries, Firenze: Edizioni Polistampa, 2010, 2 voll.

MOGARRO, Maria João (ed.). Educação e património cultural. Escolas, objectos e práticas. Lisboa: Colibrì, 2013.

MOGARRO, Maria João. Des objets qui racontent des histoires: le patrimoine educatif dans l'internationalisation des theories et des pratiques pedagogiques, La Rivista. Études culturelles italiennes Sorbonne Universités. Paris: University press, v. 2, 149-159, 2014.

PACIARONI, Lucia. II patrimonio storico-educativo tra ricerca e didattica della storia. A proposito di un importante seminario di studi, History of Education \& Children's Literature. Macerata: Eum, v. XIII, n. 1, p. 637-644, 2018.

PIZZIGONI, Francesca Davida. The pedagogic museums as a tool for historiographical research. A database for alalysis through their presence on the Internet. History of Education \& Children's Literature. Macerata: Eum, v. VII, n. 2, p. 557-578, 2012.

POMANTE, Luigiaurelio; BRUNELLI, Marta. Un recente colloquio internazionale di studi sulla cultura materiale della scuola e sulle nuove sfide che attendono la ricerca storicoeducativa, History of Education \& Children's Literature. Macerata: Eum, v. XII, n. 2, p 643652, 2017.

RAICICH, Marino. Scuola, cultura e politica da De Sanctis a Gentile, Pisa: Nistri-Lischi, 1982.

RUIZ BERRIO, Julio (ed.). El patrimonio histórico-educativo: su conservación y estudio. Madrid: Editorial Biblioteca Nueva, 2010.

RUIZ BERRIO, Julio. (Ed.). La cultura escolar de Europa: tendencias historicas emergente. Madrid: Editorial Biblioteca Nueva, 2000.

SANI, Roberto. For a history of childhood and of his education in contemporary Italy. Interpretations and perspectives of research. Cadernos de História da Educação. Uberlândia: EDUFU, v. 15, n. 2, 2016, p. 808-862.

SANI, Roberto. History of Education in Modern and Contemporary Europe: New Sources and Lines of Research. History of Education Quarterly. Cambride: University press of Cambridge, v. 53, n. 2, p. 184-195, 2013.

SANI, Roberto. La storia dell'educazione e della letteratura per l'infanzia in Italia tra adempimenti ANVUR e nuove prospettive di crescita culturale e di internazionalizzazione. History of Education \& Children's Literature. Macerata: Eum, v. XII, n. 2, 563-570, 2017. 
SANI, Roberto. Nuove tendenze nella ricerca storico-educativa. In: MACCHIETTI, Sira Serenella; SERAFINI, Giuseppe (ed.). La ricerca sull'educazione tra pedagogia e storia. Lecce: Pensa Multimedia, 2008, p. 67-75.

SOMOZA RODRÍGUEZ, Miguel. Museología de la educación: divulgación cultural, atractivo turístico o práctica historiográfica?. In: MEDA, Juri; BADANELLI, Ana Maria (ed.). La historia de la cultura escolar en Italia y en España: presupuestos y perspectivas. Actas del I Workshop Italo-Español de Historia de la Cultura Escolar (Berlanga de Duero, 14-16 de noviembre de 2011). Macerata: EUM, 2013, p. 141-166.

VIÑAO FRAGO, Antonio. La historia material e immaterial de la escuela: memoria, patrimonio y educación. Educação. Minas Gerais: Universidade Federal de Minas Gerais, v. 35, n. 1, p. 7-17, 2012.

VIÑAO FRAGO, Antonio. La memoria escolar: restos y huellas, recuerdos y olvidos. In: Homenaje al profesor Alfonso Capitán. Murcia: Universidad de Murcia, 2005, p. 739-758.

VIÑAO FRAGO, Antonio. Memoria, patrimonio y educación. Educatio Siglo XXI. Revista de la Facultad de Educación de la Universidad de Murcia, Murcia. Universidad de Murcia, v. 28, n. 2, p. 17-42, 2010.

YANES-CABRERA, Cristina; MEDA, Juri; VIÑAO FRAGO, Antonio (ed.). School Memories: New Trends in the History of Education. Cham: Springer, 2017.

Universidade do Estado de Santa Catarina - UDESC Programa de Pós-Graduação em Educação - PPGE 